\title{
Şanlıurfa ili buğday ekim alanlarında bulunan yabancı ot türlerinin, yaygınlık ve yoğunluklarının belirlenmesi
}

\section{Determination of weed species and their frequency and density in wheat cultivation areas of Şanlıurfa province, Turkey}

\author{
Erdal ATEŞ ${ }^{1^{*}}$, ilhan Üremiş ${ }^{2}$ iD \\ ${ }^{1}$ Diyarbakır Zirai Mücadele Araştırma Enstitüsü Müdürlüğü, Diyarbakır \\ ${ }^{2}$ Hatay Mustafa Kemal Üniversitesi Ziraat Fakültesi, Bitki Koruma Bölümü, Hatay
}

To cite this article:

Ateş, E. \& Üremiş, İ. (2020). Şanlıurfa ili buğday ekim alanlarında bulunan yabancı ot türlerinin, yaygınlık ve yoğunluklarının belirlenmesi. Harran Tarım ve Gıda Bilimleri Dergisi, 24(1): 33-43.

DOI: $10.29050 /$ harranziraat.612049

Address for Correspondence: Erdal ATEŞ

e-mail:

erdal.ates@tarimorman.gov.tr

\section{Received Date:}

27.08.2019

Accepted Date:

24.02.2020

(C) Copyright 2018 by Harran University Faculty of Agriculture. Available on-line at www.dergipark.gov.tr/harranziraat

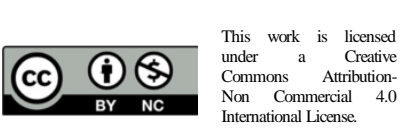

\section{öz}

Şanlıurfa ili buğday ekim alanlarında bulunan yabancı otların tespit çalışmaları 2015 ve 2016 yıllarında 10 ilçede toplam 250 tarlada yürütülmüştür. Tespit edilen yabancı ot türlerinin yaygınlıkları, yoğunlukları, özel ve genel kaplama alanları hesaplanmıştır. Yapılan sürvey çalışmaları sonucunda; 27 familyaya ait 101 cins ve 121 yabancı ot türü belirlenmiştir. Şanlıurfa'da yapılan çalışmalar sonucunda tüm ilçelerde Avena sterilis L., Sinapis arvensis L.'in rastlama sıklığı \%50'den fazla bulunmuştur. Şanlıurfa il genelinde rastlama sıklığı \%20 ve yoğunluğu $1 \mathrm{bitki} / \mathrm{m}^{2,}$ den fazla olan türler sırasıyla; Avena sterilis (11.51 bitki/m²), Lolium spp. L., $\left(4.96 \mathrm{bitki} / \mathrm{m}^{2}\right)$, Sinapis arvensis $\left(3.26 \mathrm{bitki} / \mathrm{m}^{2}\right)$, Hordeum spontaneum L., (3.21 bitki $\left./ \mathrm{m}^{2}\right)$, Galium tricornutum (3.05 bitki $\left./ \mathrm{m}^{2}\right)$, Convolvulus arvensis $\left(2.93 \mathrm{bitki} / \mathrm{m}^{2}\right)$ ve Papaver spp. $(1.33$ bitki/m²' dir.

Anahtar Kelimeler: Şanlıurfa, Buğday, Yabancı ot, Sürvey, Yaygınlık ve yoğunluk

\section{ABSTRACT}

During 2015 and 2016 growing seasons, determination of weed species were performed in wheat cultivation areas of Şanlıurfa province, was carried out in a total of 250 fields in 10 districts. The prevalence, density, specific and general coverage area of identified weed species were calculated. Based on the sürvey analysis in the wheat fields, 121 weed species belonging to 101 genus of 27 families were determined in Şanlıurfa province. The density of the species which are incidence frequency $20 \%$ and having more than one plant for per square meter are respectively; Avena sterilis L.(11.51 plants $\left./ \mathrm{m}^{2}\right)$, Lolium spp. (4.96 plants $\left./ \mathrm{m}^{2}\right)$, Sinapis arvensis (3.26 plants $\left./ \mathrm{m}^{2}\right)$, Hordeum spontaneum (3.21 plants $\left.\mathrm{m}^{2}\right)$, Galium tricornutum (3.05 plants $\left./ \mathrm{m}^{2}\right)$, Convolvulus arvensis (2.93 plants $\left./ \mathrm{m}^{2}\right)$, Papaver spp. (1.33 plants $\left./ \mathrm{m}^{2}\right)$.

Key Words: Şanlıurfa, Wheat, Weeds, Survey, Frequency

\section{Giriş}

İnsan beslenmesinde önemli bir besin maddesi olan ve tarım tarihinin akışında güncelliğini her zaman koruyan buğday; ekmek yapımına uygun ve rakipsiz olması, tarımının kolay ve tamamen mekanizasyona uygunluğu, yetiştirici hatalarını ve olumsuz koşulları belli oranda telafi edebilmesi, pazarlama, taşıma, depolama ve işlenme kolaylıklarına sahip olması buğday tarımını teşvik etmektedir. Bunlardan dolayı buğday sıradan bir bitki olmak yerine, geçmişte ve zamanımızda olduğu gibi, gelecekte de stratejik bir bitki olma özelliğini koruyacağı beklenmektedir (Akkaya, 1994; Kün, 1996; Arısoy ve Oğuz, 2005; Acıbuca, 2010). 
Dünya genelinde buğday üretim alanı ve üretim miktarı açısından 124 ülkede toplam 242 182340 hektar alanda 832888498 ton buğday üretimi gerçekleştirilmiştir. Ülkelere göre, buğday ekim alanları açısından yapılan değerlendirmede Hindistan 29650000 ha alan ile ilk sırayı alırken Türkiye 7936790 ha üretim alanıyla 10. sırada yer almaktadır. Üretim miktarı açısından 121930 527 ton buğday üretimiyle Çin'in ilk sırada olduğu listede Türkiye 12. sıradadır (Anonymous, 2016). Türkiye'de Tüik verilerine göre 22186681 ton buğday üretimi yapılmış olup bu miktarın sadece 3633912 tonu Güneydoğu Anadolu Bölgesi'nden karşılanmaktadır. Ülkemiz buğday üretiminde Konya (2.045.298 ton), Ankara (1.205.676 ton) ve Diyarbakır (1.151.524 ton)'dan sonra 4. sırada yer alan Şanlıurfa 267373 ha buğday ekim alanına sahip olup bu alandan 759669 ton buğday üretimi gerçekleştirilmektedir (Anonim, 2016).

Buğday bitkisinin suyuna ve besinine ortak olup kültür bitkisiyle rekabete giren yabancı otların neden olduğu verim kaybı \%20-40 civarındadır (Zimdahl, 2018). Yabancı otlar verimi yaklaşık \%30 oranında düşürmekle beraber kaliteyi de olumsuz etkilemektedirler (Güncan, 2016). Özellikle buğday tohumlarına karışan yabancı ot tohumları tohumluk kalitesini düşürmekte, başka alanlara yabancı ot tohumlarının bulaşmasına neden olmakta, zehirli yabancı ot tohumları hem insan hem de hayvan sağlığını tehdit etmektedir (Direk ve Gül, 2003; Bozkurt, 2018). Ayrıca yabancı otlar buğday yetiştiriciliğinde sorun olduğu gibi buğdayın işlenmesinde de ciddi sorun teşkil etmektedir. Özellikle gıda sanayisinde buğdayın öğütülmesi aşamasında ürünle bulaşık yabancı ot tohumları değirmenin valslerine zarar vermekle birlikte unun ve irmiğin rengini, bileşimini olumsuz etkileyerek üretim bandında fiziksel ve kimyasal kalite özelliklerini yitirmesine, dolayısıyla işlenmiş buğdaydan üretilen ürünün yurtiçinde ve yurtdışında rekabet gücünün ve pazar değerinin düşmesine neden olmaktadır (Özer ve ark., 1998; Bozkan, 2013).

Ülkemizde buğday alanlarında farklı bölgelerde ve farklı zamanlarda Kuntay (1944), Bilgir (1965), Uygur (1985), Taştan ve Erciş (1991), Mennan
(1993), Zel (1994), Sırma ve Güncan (1997), Tepe (1997), Kaya ve Zengin (2000), Tursun (2002), Üstüner ve Altın (2003), Gökalp ve Üremiş (2015), Gürsu ve Kara (2016) tarafından çok sayıda çalışmalar yapılmıştır. Söz konusu çalışmalar Akdeniz, Doğu Anadolu, Ege, Güneydoğu Anadolu, İç Anadolu, Karadeniz ve Marmara Bölgesi buğday ekim alanlarında yabancı otların yaygınlık ve yoğunluklarının belirlenmesine yönelik yapılan çalışmaları içermektedir. Bu çalışmalarda geniş yapraklı yabancı otlar arasında genel olarak; Convolvulus arvensis, Galium spp., Polygonum spp., Sinapis arvensis, Vicia spp.; dar yapraklı yabancı otlar arasında ise Alopecurus myosuroides, Avena spp., Phalaris spp., Lolium spp.'nin yaygın ve yoğun olduğu bildirilmiştir.

Buğdayın üretiminde ve işlenmesinde yabancı otlardan kaynaklanan sorunların asgari düzeyde tutulması için; buğday ekim alanlarında etkili mücadele programlarının uygulanması gerekmektedir. Uygulanacak yöntemlerde başarı sağlanması buğday alanlarında yoğun görülen yabancı ot türlerinin saptanmasıyla doğrudan ilişkilidir. Belirlenen türlerin yaprak formu, yaşam süresi, çimlenme koşulları ve çoğalma şekli gibi özelliklerinin bilinmesi söz konusu türlere karşı mücadelenin yöntemini belirlemede önemli rol oynamaktadır. Ayrıca, küresel iklim değişikliği, tarım alanlarında kullanılan alet - ekipman ve kimyasalların yaygınlaşması, modern sulama sistemleriyle suya erişim imkanlarının iyileştirilmesi, gelişen ulaşım ağları ve çeşitliliği, kültür bitkilerinde geliştirilen yeni çeşitler; yabancı otların davranışlarını, topluluk oluşturma durumlarını ve yayılma hızlarını etkilemektedir (Karaca, 2010). Dolayısıyla ülkemiz için büyük öneme sahip buğday tarımında, yabancı otlardan kaynaklanan verim kayıplarını ve üretim maliyetlerini asgari düzeyde tutmak için hazırlanacak mücadele programlarına temel oluşturmak için belirli aralıklarla sürvey çalışmalarına ihtiyaç duyulmaktadır (Gökalp ve Üremiş, 2015). Bu nedenle buğday alanlarında bulunan yabancı ot türleri, yaygınlık ve yoğunlukları saptanmalı, sorun oluşturan türlerin popülasyon dalgalanmaları ve bu popülasyona 
dahil olan yeni türlerin durumları periyodik olarak takip edilmelidir. Bu beklentiler doğrultusunda yapılan bu çalışmada Şanlıurfa ili buğday alanlarında bulunan yabancı ot türlerinin yaygınlıklarının ve yoğunluklarının belirlenmesi amaçlanmıştır.

\section{Materyal ve Metot}

Çalışmanın ana materyalini buğday tarlalarındaki yabancı otlar ve bunların ölçümünde kullanılan ahşap çerçeveler oluşturmaktadır. Çalışmanın yapıldığı Şanlıurfa ili Güneydoğu Anadolu Bölgesi'nin Orta Fırat Bölümü'nde yer almakta olup, Güneydoğu Torosların orta kısmının güney etekleri üzerinde olup $37^{\circ} 49^{\prime} 12^{\prime \prime}-40^{\circ} 10^{\prime} 00^{\prime \prime}$ doğu meridyeni ile $36^{\circ} 41^{\prime}-37^{\circ} 57^{\prime}$ kuzey paralelinde bulunmaktadır. Şanlıurfa'da karasal iklim özelliği ağır basmaktadır. Yazları çok kurak ve sıcak, kışları yağışlı, nispeten ılık geçmektedir. Karlı ve donlu gün sayısı oldukça azdır (Anonim, 2012).

Yabancı otların tür, yaygınlık ve yoğunluklarının belirlenmesiyle ilgili sürvey çalışmalarının yürütüldüğü buğday ekim alanları Tarım ve Orman Bakanlığı Şanlıurfa ì Müdürlüğünden alınan bilgiler doğrultusunda belirlenmiştir. Örnekleme sayısının belirlenmesinde her bir ilçe için toplam ekiliş alanı üzerinden "tartılı ortalama yöntemi" (Bora ve Karaca, 1970) kullanılarak hesaplanmış olup 5'in altında kalan tarla örneklemeleri 5'e tamamlanmıştır. Sürvey çalışmaları Şanlıurfa ilinde 2015-2016 yıllarının Mart, Nisan, Mayıs, Haziran aylarında yürütülmüştür. Verilerin değerlendirilmesinde ilçe merkezleri başlangıç alınarak diğer ilçelere doğru gidilerek her 10 km'de bir durularak en yakın buğday tarlasına tesadüfi olarak girilmiştir. Sürvey çalışmaları Akçakale, Bozova, Ceylanpınar, Eyyübiye, Haliliye, Harran, Hilvan, Karaköprü, Siverek ve Viranşehir ilçelerine ait toplam 250 tarlada yürütülmüştür. Örnekleme yapılan alanlarda çerçeve atımına tarla kenarından 5-10 metre içerden başlanmış olup buğday tarlasında 1 da'lık alan dikkate alınarak ve her tarlada rastlantısal olarak dört defa $1 \mathrm{~m}^{2 \prime l}$ lik çerçeve atılarak çerçeveye giren yabancı otların türleri ve yoğunlukları (bitki/ $\mathrm{m}^{2}$ ) kaydedilmiştir (Orel, 1996). Ayrıca çerçeveye giren her bir türün kaplama alanları hesaplanarak kaydedilmiştir. Bitki örneklerinin tanısında Davis (1965-1988)'den yararlanılmıştır. Yabancı otların isimlendirilmeleri Uluğ ve ark. (1993)'e göre yapılmıştır. Rastlama sıklıklarının belirlenmesinde aritmetik yüzde esas alınarak hesaplama yapılmıştır (Uygur, 1985). Hesaplanan yabancı ot yaygınlıklarının değerlendirilmesinde ise Pamukoğlu (2011)'ndan uyarlanan skala kullanılmıştır. Buna göre,

$$
\begin{aligned}
& \text { ÇR : Çok yaygın > \%50.0; } \\
& \text { YR : Yaygın } \% 25.0 \text { - } \% 49.9 ; \\
& \text { ÖR : Önemli \%10.0 - \%24.9; } \\
& \text { NR : Nadir <9.9 olarak sınıflandırılmıştır. }
\end{aligned}
$$

Yabancı otların yoğunluklarının belirlenmesinde de aritmetik ortalama esas alınarak değerlendirme yapılmıştır. Bir tarlada her bir yabancı ot için yapılan sayımlar sonucu elde edilen değer o tarlada sayım yapılan toplam alana bölünerek yabancı ot yoğunluğu (bitki/m²) bulunmuştur (Üstüner ve Güncan, 2002). Hesaplanan yabancı ot yoğunluklarının değerlendirilmesinde ise Pamukoğlu (2011)'dan uyarlanan skala ile ifade edilmiştir. Buna göre;
A: $>3.00 \mathrm{bitki} / \mathrm{m}^{2}$
B: $2.00-2.99 \mathrm{bitki} / \mathrm{m}^{2}$
C: $1.00-1.99 \mathrm{bitki} / \mathrm{m}^{2}$
D: $0.10-0.99 \mathrm{bitki} / \mathrm{m}^{2}$
E: $0.10>\mathrm{bitki} / \mathrm{m}^{2}$ şeklinde sınıflandırılmıştır.

\section{Bulgular ve Tartışma}

Sürvey çalışmalarında tespit edilen yabancı otların türleri, yaygınlık ve yoğunlukları Çizelge 1 'de verilmiştir. 
Çizelge 1. Şanlıurfa ili buğday alanlarında görülen yabancı otlar

Table 1. Weeds seen in wheat fields of Sanliurfa province

\begin{tabular}{|c|c|c|c|}
\hline Bilimsel İsmi & Türkçe İsmi & Yaygınlık & Yoğunluk \\
\hline Scientific name & Native name & Frequency & Denstity \\
\hline
\end{tabular}

Ammi visnaga (L.) Lam.

Bifora radians Bieb.

Caucalis platycarpos L.

Conium maculatum L.

Daucus carota L.

Eryngium campestre L.

Falcaria vulgaris Bernh.

Scandix pecten-veneris L.

Tordylium spp.

Turgenia latifolia (L.) Hoffm.

\section{Fam. ARACEAE}

Arum sp.

\section{Fam. ARISTOLOCHIACEAE}

Aristolachia maurorum L.

Fam. ASTERACEAE (Compositae)

Acroptilon sp.

Anthemis arvensis L.

Bupleurum rotundifolium $\mathrm{L}$.

Carduus nutans $\mathrm{L}$.

Carduus pycnocephalus L.

Carthamus sp.

Centaurea depressa Bieb.

Centaurea iberica Trevis ex Sprengel

Centaurea solstitialis L.

Cichorium intybus $\mathrm{L}$.

Cirsium spp.

Gundelia tournefortii L.

Lactuca serriola $\mathrm{L}$.

Matricaria chamomilla L.

Notobasis syriaca (L.) Cass.

Onopordum spp.

Senecio vernalis Waldst. and Kit.

Senecio vulgaris $\mathrm{L}$.

Silybum marianum L.

Sonchus asper (L.) Hill

Sonchus oleraceus L.

Taraxacum officinale (L.) Weber ex F.H.Wigg.

Xanthium strumarium $\mathrm{L}$.

\section{Fam. BERBERIDACEA}

Bongardia chrysogonum (L.) Spach.

Fam. BORAGINACEAE

Anchusa azurea Miller.

Buglossoides arvensis L.

Fam. BRASSICACEAE (Cruciferae)

Alyssum alyssoides (L.) L.

Boreava orientalis Jaub and Spach

Capsella bursa-pastoris (L.) Medik.

Cardaria draba (L.) Desv.

Descurainia sophia (L.) Webb ex Prant.

Hirschfeldia incana (L.) Lagr.-Fossat

Isatis tinctoria $\mathrm{L}$.

Myagrum perfoliatum L.

Neslia apiculata Fisch. and Mey.

Neslia paniculata (L.) Desv

Raphanus raphanistrum $\mathrm{L}$.

Sinapis alba L.

Sinapis arvensis $\mathrm{L}$.

Sisymbrium sp.

Kürdan otu
Kokarot
Küçük pıtrak
Baldıran otu
Yabani havu
Boğa dikeni
Falçata otu
Zühre tarağı
Geyik otu
Pıtrak

Yılan yastığı

Loğusa otu

Kekre

Tarla köpek papatyası

Tavşan kulağı

Eğik başlı kangal

Saka dikeni

Boyacı dikeni

Yatık gökbaş

Kısa dikenli gelin düğmesi

Güneş dikeni

Yabani hindiba

Köygöçüren

Kenger

Dikenli yabani marul

Hakiki papatya

Suriye dikeni

Eşek dikeni

Kanarya otu

Adi kanarya otu

Meryemana dikeni

Dikenli eşek marulu

Adi eşek marulu

Karahindiba

Domuz pıtrağı

Çatlak otu

Sığır dili

Taşkesen otu

Hakiki kuduz otu

Sarı ot

Çoban çantası

Yabani tere

Uzun süpürge otu

Melez hardal

Yabani çivit otu

Gönül hardalı

Trakya hardalı

Toplu iğne hardalı

Yabani turp

Akhardal

Yabani hardal

Bülbül otu
NR D

NR

NR

NR

NR

NR

NR

NR

NR

NR

NR

C

NR $\quad$ C

NR E

OR C

NR D

NR D

ÖR D

NR D

NR E

NR D

NR A

NR $\quad E$

NR D

NR E

NR D

NR D

NR $\quad E$

NR D

$N R \quad D$

NR $\quad E$

ÖR D

ÖR C

NR D

NR E

NR C

NR

E

NR $\quad D$

ÖR A

NR $\quad D$

ÖR D

ÖR B

NR B

NR D

ÖR $B$

ÖR D

NR C

NR D

NR $\quad D$

NR D

NR $\quad D$

ÇR A

NR D


Ateş ve Üremiş, 2020. Harran Tarım ve Gıda Bilimleri Dergisi, 24(1): 33-43

\begin{tabular}{|c|c|c|c|}
\hline $\begin{array}{l}\text { Bilimsel İsmi } \\
\text { Scientific name }\end{array}$ & $\begin{array}{l}\text { Türkçe İsmi } \\
\text { Native name }\end{array}$ & $\begin{array}{l}\text { Yaygınlık } \\
\text { Frequency }\end{array}$ & $\begin{array}{l}\text { Yoğunluk } \\
\text { Denstity }\end{array}$ \\
\hline Texiera glastifolia (DC.) Jaub. et Spach & Tesbih taneli hardal & NR & $E$ \\
\hline Thlaspi arvense $\mathrm{L}$. & Tarla akçaçiçeği & NR & D \\
\hline \multicolumn{4}{|l|}{ Fam. CARYOPHYLLACEAE } \\
\hline Capparis sp. & Kapari & NR & B \\
\hline Cerastium sp. & Boynuz otu & NR & $\mathrm{C}$ \\
\hline Silene colorata Poir. & Renkli nakıl & NR & D \\
\hline Silene conica $\mathrm{L}$. & Konik nakıl & NR & E \\
\hline Stellaria media (L.) Vill. & Serçe dili & NR & A \\
\hline Vaccaria pyramidata Medik. & Arap baklası & ÖR & D \\
\hline \multicolumn{4}{|l|}{ Fam. . GUTTIFERAE (Clusiaceae) } \\
\hline Hypericum perforatum L. & Sarı kantaron & NR & $\mathrm{D}$ \\
\hline \multicolumn{4}{|l|}{ Fam. CONVOLVULACEAE } \\
\hline Convolvulus arvensis $\mathrm{L}$. & Tarla sarmaşı̆̆ı & YR & B \\
\hline Convolvulus betonicifolius Miller & Tüylü tarla sarmaşığı & NR & $\mathrm{C}$ \\
\hline Convolvulus galaticus Rostan ex Choisy & Boz sarmaşık & NR & D \\
\hline \multicolumn{4}{|l|}{ Fam. DIPSACACEAE } \\
\hline Cephalaria syriaca (L.) Schrader & Pelemir & ÖR & C \\
\hline \multicolumn{4}{|l|}{ Fam. EUPHORBIACEAE } \\
\hline Euphorbia cyparissias L. & Servi sütleğen & NR & D \\
\hline Euphorbia falcata L. & Tırpanvari sütleğen & NR & D \\
\hline Euphorbia sp. & Sütleğen & NR & $\mathrm{D}$ \\
\hline \multicolumn{4}{|l|}{ Fam. FABACEAE (Leguminosae) } \\
\hline Coronilla scorpioides (L.) Koch. & Akrep kuyruğu & NR & $\mathrm{E}$ \\
\hline Lathyrus sativus L. & Mürdümük & NR & E \\
\hline Lens culinaris Medik & Kendi gelen mercimek & NR & A \\
\hline Medicago radiata $\mathrm{L}$. & Yonca & NR & D \\
\hline Melilotus officinalis (L.) Desr. & Kokulu sarı yonca & NR & C \\
\hline Pisum sativum $\mathrm{L}$. & Tarla bezelyesi & NR & C \\
\hline Trifolium sp. & Üçgül & ÖR & C \\
\hline Vicia ervilia (L.) Willd. & Burçak & NR & $\mathrm{E}$ \\
\hline Vicia narbonensis L. & Koca fiğ & NR & D \\
\hline Vicia sativa $\mathrm{L}$. & Yabani fiğ & ÖR & A \\
\hline \multicolumn{4}{|l|}{ Fam. GERANIACEAE } \\
\hline Erodium cicutarium (L.) L'Herit. & Dönbaba & NR & D \\
\hline Geranium spp. & Turna gagası & NR & A \\
\hline \multicolumn{4}{|l|}{ Fam. LAMIACEAE } \\
\hline Lallemantia iberica (Bieb.) Fish. and Mey. & İberya lallelmantı & NR & E \\
\hline Lamium aleppicum Boiss. et Hausskn. & Halep ballıbabası & NR & A \\
\hline Salvia spp. & Ada çayı & NR & E \\
\hline \multicolumn{4}{|l|}{ Fam. LEGUMINOSAE } \\
\hline Glycyrrhiza glabra L. & Meyan kökü & NR & C \\
\hline \multicolumn{4}{|l|}{ Fam. LILIACEAE } \\
\hline Bellevalia macrobotrys Boiss. & Koca sümbül & NR & D \\
\hline Muscari comosum (L.) Miller & Arap sümbülü & NR & D \\
\hline Ornithogalum sp. & Tükürük otu & NR & $\mathrm{E}$ \\
\hline \multicolumn{4}{|l|}{ Fam. MALVACEAE } \\
\hline Alcea sp. & Hatmi & NR & E \\
\hline Malva neglecta Wallr. & Ebegümeci & NR & C \\
\hline \multicolumn{4}{|l|}{ Fam. PAPAVERACEAE } \\
\hline Fumaria officinalis $\mathrm{L}$. & Hakiki şahtere & NR & A \\
\hline Papaver spp. & Gelincik & ÖR & c \\
\hline \multicolumn{4}{|l|}{ Fam. POACEAE } \\
\hline Aegilops spp. & Yabani buğday & ÖR & D \\
\hline Agropyron repens (L.) P. Beauv. & Otlak ayrığı & NR & D \\
\hline Alopecurus myosuroides Hudson & Tilki kuyruğu & NR & D \\
\hline Apera spica-venti $\mathrm{L}$. & Rüzgar otu & ÖR & A \\
\hline Avena fatua $\mathrm{L}$. & Yabani yulaf & NR & A \\
\hline Avena sterilis $\mathrm{L}$. & Kısır yabani yulaf & ÇR & A \\
\hline Bromus sterilis L. & KIsır brom & NR & C \\
\hline Bromus tectorum $\mathrm{L}$. & Püsküllü çayır & NR & B \\
\hline Cynodon dactylon (L.) Pers. & Köpek dişi ayrığı & NR & C \\
\hline
\end{tabular}




\begin{tabular}{|c|c|c|c|}
\hline $\begin{array}{l}\text { Bilimsel İsmi } \\
\text { Scientific name }\end{array}$ & $\begin{array}{l}\text { Türkçe İsmi } \\
\text { Native name }\end{array}$ & $\begin{array}{l}\text { Yaygınlık } \\
\text { Frequency }\end{array}$ & $\begin{array}{l}\text { Yoğunluk } \\
\text { Denstity }\end{array}$ \\
\hline Echinaria capitata (L.) Desf. & Dikenbaş çimi & NR & $\mathrm{D}$ \\
\hline Hordeum murinum $\mathrm{L}$. & Duvar arpası & NR & B \\
\hline Hordeum spontaneum C. Koch & Yabani arpa & YR & A \\
\hline Hordeum vulgare $\mathrm{L}$. & Kendi gelen arpa & NR & A \\
\hline Lolium spp. & Delice & YR & A \\
\hline Phalaris spp. & Kuşyemi & ÖR & D \\
\hline Secale cereale L. & Çavdar & NR & C \\
\hline $\begin{array}{l}\text { Sorghum halepense (L.) Pers. } \\
\text { Fam. POLYGONACEAE }\end{array}$ & Kanyaş & NR & D \\
\hline Polygonum aviculare L. & Çoban değneği & ÖR & c \\
\hline $\begin{array}{l}\text { Rumex acetosella L. } \\
\text { Fam. PORTULACACEAE }\end{array}$ & Kuzu kulağı & NR & $\mathrm{E}$ \\
\hline $\begin{array}{l}\text { Portulaca oleracea L. } \\
\text { Fam. PRIMULACEAE }\end{array}$ & Semiz otu & NR & $\mathrm{E}$ \\
\hline $\begin{array}{l}\text { Anagallis arvensis L. } \\
\text { Fam. RANUNCULACEAE }\end{array}$ & Fare kulağı & NR & C \\
\hline Adonis sp. & Kan damlası & NR & D \\
\hline $\begin{array}{l}\text { Ranunculus arvensis } \mathrm{L} . \\
\text { Fam. } \mathrm{RUBIACEAE}\end{array}$ & Tarla düğün çiçeği & ÖR & B \\
\hline Asperula orientalis Boiss. et Hohen & Doğu yapışkan otu & NR & D \\
\hline Galium aparine L. & Dilkanatan & NR & D \\
\hline $\begin{array}{l}\text { Galium tricornutum Dandy } \\
\text { Fam. SCROPHULARIACEAE }\end{array}$ & Boynuzlu yoğurt otu & ÖR & A \\
\hline Veronica arvensis $\mathrm{L}$. & Tarla yavşanı & NR & c \\
\hline Veronica hederifolia $\mathrm{L}$. & Adi yavşan otu & NR & D \\
\hline $\begin{array}{l}\text { Verbascum nigrum L. } \\
\text { Fam. SOLANACEAE }\end{array}$ & Sığır kuyruğu & NR & $\mathrm{D}$ \\
\hline Physalis spp. & Fener otu & NR & $\mathrm{E}$ \\
\hline
\end{tabular}

Çizelge 1'e göre 3'ü monokotiledon (Araceae, Liliaceae, Poaceae), 24'ü dikotiledon (Apiaceae, Aristolochiaceae, Asteraceae, Berberidaceae, Boraginaceae, Brassicaceae, Caryophyllaceae, Convolvulaceae, Dipsaceae, Euphorbiaceae, Fabaceae, Geraniaceae, Guttiferae, Lamiaceae, Leguminosae, Malvaceae, Papaveraceae, Polygonaceae, Portulacaceae, Primulaceae, Ranunculaceae, Rubiaceae, Scrophulariaceae, Solanaceae) olmak üzere toplam 27 familyaya ait 101 yabancı ot cinsi ve 121 yabancı ot türü saptanmıştır. Bunların 21 türü dar yapraklı, 100 türü ise geniş yapraklıdır. Hayat sürelerine göre belirlenen türlerin 27'si çok yıllık (ÇY) olup 68'i tek yıllık (TY) ve 4'ü ise iki yıllık (iY)'tır. Ayrıca 4'ü TYÇY, 11'i TY-iY, 5'i TY - iY - çY ve 2'si iY - çY'dir.

Şanlıurfa il geneli buğday alanlarında yabancı otların yaygınlığı açısından; çok rastlanan (ÇR, > $\% 50.0)$ S. arvensis ve $A$. sterilis olmak üzere iki yabancı ot türü kaydedilmiştir. Yaygın oranda (YR, \%25.0 - \%49.9) ise C. arvensis, H. spontaneum, Lolium spp. olmak üzere 3 tür saptanmıştır. Önemli oranda yaygın (ÖR, \%10.0 - \%24.9) görülen 20 tür saptanmış olup bu türler arasında Papaver spp., G. Tricornutum ve S. marianum ilk sıralarda yer almaktadır. Nadir oranda yaygın (NR, < \%9.9) görülen 96 tür kaydedilmiştir. E. campestre, $H$. murinum, $V$. arvensis ilk 3 tür olarak yer almıştır

" $A$ " seviyesinde yoğun 16 tür kaydedilmiş olup $H$. spontaneum, A. Sterilis ve L. culinaris türleri ilk sıralarda yer almaktadır. "B" seviyesinde 8 tür kaydedilmiştir. Bu türler arasında $C$. arvensis, $R$. arvensis ve $C$. draba ilk 3 sırada yer almaktadır. " $C$ " seviyesinde yoğun 22 tür kaydedilmiştir. illk 3 sırada $M$. neglecta, Trifolium spp. ve $V$. arvensis türleri yer almaktadır. Türlerin yoğunluğuna göre " $\mathrm{D}$ " seviyesinde 55 tür kaydedilmiştir. Adonis sp., S. halepense ve $T$. latifolia türleri ön sıralarda yer almaktadır. "E" seviyesinde ise 20 yabancı ot türü kaydedilmiş olup ilk 3 sırada Acroptilon sp., $N$. Syriaca ve $S$. conica türleri yer almaktadır.

Şanlıurfa il genelinde yaygınlığı \%20 ve yoğunluğu $\mathrm{m}^{2 \text { 'de }} 1$ bitkiden fazla olan türlerin yaygınlığı, yoğunluğu, özel ve genel kaplama alanları il ve ilçeler bazında Çizelge 2.'de verilmiştir. 
Çizelge 2. Şanlıurfa il ve ilçelerinde görülen önemli yabancı ot türlerinin yaygınlığı, yoğunluğu, özel ve genel kaplama alanları Table 2. Frequency and, density and, specific and, general coverage area found as the some major weed species in Şanlıurfa province and district

\begin{tabular}{|c|c|c|c|c|}
\hline $\begin{array}{c}\text { Tür } \\
\text { Species }\end{array}$ & $\begin{array}{l}\text { Yoğunluk (bitki/m²) } \\
\left.\text { Denstity (plant } / \mathrm{m}^{2}\right)\end{array}$ & $\begin{array}{l}\text { Yaygınlık (\%) } \\
\text { Frequency (\%) }\end{array}$ & $\begin{array}{l}\text { Ö.K.A. (\%) } \\
\text { S.C.A. (\%) }\end{array}$ & $\begin{array}{l}\text { G.K.A. (\%) } \\
\text { G.C.A. (\%) }\end{array}$ \\
\hline \multicolumn{5}{|l|}{ îl geneli } \\
\hline Avena sterilis & 11.51 & 86.88 & 15.30 & 11.35 \\
\hline Sinapis arvensis & 3.26 & 84.71 & 22.89 & 16.06 \\
\hline Convolvulus arvensis & 2.93 & 43.30 & 7.45 & 2.76 \\
\hline Lolium spp. & 4.96 & 42.12 & 6.08 & 1.58 \\
\hline Hordeum spontaneum & 3.21 & 35.55 & 4.37 & 0.89 \\
\hline Papaver spp. & 1.33 & 24.48 & 2.63 & 0.46 \\
\hline Galium tricornutum & 3.05 & 23.70 & 4.83 & 0.92 \\
\hline \multicolumn{5}{|l|}{ Akçakale } \\
\hline Sinapis arvensis & 3.39 & 96.67 & 30.64 & 26.91 \\
\hline Avena sterilis & 8.11 & 95.00 & 11.80 & 10.35 \\
\hline Hordeum spontaneum & 7.09 & 35.00 & 9.08 & 1.95 \\
\hline Convolvulus arvensis & 1.59 & 35.00 & 6.48 & 2.13 \\
\hline Lolium spp. & 6.33 & 23.33 & 10.45 & 1.95 \\
\hline \multicolumn{5}{|l|}{ Ceylanpınar } \\
\hline Avena sterilis & 8.76 & 68.75 & 12.20 & 6.48 \\
\hline Convolvulus arvensis & 3.61 & 34.38 & 10.77 & 1.75 \\
\hline Hordeum spontaneum & 1.98 & 38.13 & 3.04 & 0.51 \\
\hline Lolium spp. & 1.44 & 27.50 & 2.45 & 0.17 \\
\hline Aegilops spp. & 1.28 & 22.50 & 1.12 & 0.34 \\
\hline \multicolumn{5}{|l|}{ Eyyübiye } \\
\hline Avena sterilis & 4.36 & 100 & 6.60 & 6.17 \\
\hline Sinapis arvensis & 4.06 & 100 & 20.63 & 20.63 \\
\hline Lolium spp. & 8.33 & 83.33 & 7.50 & 5.00 \\
\hline Capsella bursa-pastoris & 1.06 & 83.33 & 1.65 & 1.11 \\
\hline Veronica arvensis & 5.61 & 66.67 & 13.12 & 10.19 \\
\hline Convolvulus arvensis & 4.70 & 66.67 & 10.50 & 5.50 \\
\hline Stellaria media & 10.10 & 50.00 & 42.35 & 28.24 \\
\hline Galium tricornutum & 5.67 & 50.00 & 7.40 & 2.47 \\
\hline Lamium aleppicum & 3.07 & 50.00 & 4.10 & 2.74 \\
\hline Hordeum spontaneum & 2.67 & 50.00 & 4.00 & 1.34 \\
\hline Anthemis arvensis & 2.50 & 50.00 & 10.07 & 6.71 \\
\hline Fumaria officinalis & 1.10 & 50.00 & 1.60 & 1.07 \\
\hline Apera spica-venti & 5.00 & 33.33 & 4.00 & 1.34 \\
\hline Centaurea solstitialis & 3.67 & 33.33 & 12.67 & 8.45 \\
\hline Trifolium spp. & 1.50 & 33.33 & 3.00 & 1.00 \\
\hline \multicolumn{5}{|l|}{ Haliliye } \\
\hline Lolium spp. & 3.52 & 87.50 & 4.40 & 2.18 \\
\hline Avena sterilis & 7.92 & 87.50 & 12.69 & 7.49 \\
\hline Sinapis arvensis & 4.45 & 85.71 & 33.37 & 24.68 \\
\hline Convolvulus arvensis & 3.99 & 55.36 & 7.97 & 5.01 \\
\hline Trifolium spp. & 2.81 & 46.43 & 5.58 & 2.65 \\
\hline Papaver spp. & 3.44 & 41.07 & 8.17 & 2.16 \\
\hline Glycyrrhiza glabra & 1.56 & 41.07 & 8.67 & 1.60 \\
\hline Fumaria officinalis & 7.27 & 39.29 & 14.57 & 4.75 \\
\hline Galium tricornutum & 1.11 & 37.50 & 1.56 & 0.78 \\
\hline Malva neglecta & 3.00 & 33.93 & 6.00 & 1.50 \\
\hline Polygonum aviculare & 1.89 & 28.57 & 3.56 & 1.02 \\
\hline Veronica arvensis & 4.91 & 26.79 & 8.34 & 2.13 \\
\hline Hordeum vulgare & 1.17 & 25.00 & 1.17 & 0.59 \\
\hline \multicolumn{5}{|l|}{ Harran } \\
\hline Avena sterilis & 2.57 & 100 & 3.44 & 3.19 \\
\hline Sinapis arvensis & 1.19 & 100 & 12.60 & 10.63 \\
\hline \multicolumn{5}{|l|}{ Hilvan } \\
\hline Sinapis arvensis & 6.68 & 100 & 28.31 & 26.12 \\
\hline Avena sterilis & 13.69 & 79.17 & 16.35 & 13.81 \\
\hline Convolvulus arvensis & 3.19 & 55.56 & 8.29 & 3.99 \\
\hline Papaver spp. & 1.50 & 45.83 & 1.91 & 0.66 \\
\hline
\end{tabular}


Ateş ve Üremiş, 2020. Harran Tarım ve Gıda Bilimleri Dergisi, 24(1): 33-43

\begin{tabular}{lcccc}
\hline $\begin{array}{c}\text { Tür } \\
\text { Species }\end{array}$ & $\begin{array}{c}\left.\text { Yoğunluk (bitki/m } \mathbf{m}^{2}\right) \\
\text { Denstity }\left(\text { plant } / \mathrm{m}^{2}\right)\end{array}$ & $\begin{array}{c}\text { Yaygınlık (\%) } \\
\text { Frequency (\%) }\end{array}$ & $\begin{array}{c}\text { Ö.K.A. (\%) } \\
\text { S.C.A. (\%) }\end{array}$ & $\begin{array}{c}\text { G.K.A. (\%) } \\
\text { G.C.A. (\%) }\end{array}$ \\
\hline Lolium spp. & 3.38 & 38.89 & 3.05 & 0.41 \\
Galium tricornutum & 3.54 & 33.33 & 6.72 & 1.65 \\
Buglossoides arvensis & 3.19 & 26.39 & 8.32 & 3.62 \\
Hordeum spontaneum & 1.31 & 26.39 & 1.31 & 0.22 \\
Hordeum vulgare & 18.7 & 23.61 & 24.28 & 5.83 \\
Ranunculus arvensis & 1.72 & 23.61 & 3.77 & 0.76 \\
Hirschfeldia incana & 2.90 & 22.22 & 12.98 & 4.33 \\
Siverek & & & & \\
Avena sterilis & 19.78 & 97.06 & 24.35 & 19.86 \\
Sinapis arvensis & 2.47 & 85.78 & 16.11 & 11.15 \\
Galium tricornutum & 2.98 & 72.79 & 4.87 & 2.69 \\
Convolvulus arvensis & 3.33 & 48.04 & 7.48 & 3.44 \\
Lolium spp. & 9.08 & 38.97 & 11.69 & 3.44 \\
Papaver spp. & 1.24 & 35.54 & 2.03 & 0.56 \\
Buglossoides arvensis & 3.52 & 34.31 & 5.05 & 1.46 \\
Hordeum spontaneum & 2.55 & 33.09 & 3.60 & 1.04 \\
Ranunculus arvensis & 3.10 & 28.92 & 6.82 & 2.11 \\
Vicia sativa & 3.88 & 21.81 & 8.43 & 2.53 \\
Cephalaria syriaca & 1.31 & 21.32 & 7.36 & 0.73 \\
Viranşehir & & & & \\
Avena sterilis & 11.38 & 88.89 & 18.64 & 13.59 \\
Sinapis arvensis & 2.67 & 88.89 & 29.58 & 16.43 \\
Convolvulus arvensis & 3.35 & 44.44 & 7.54 & 2.77 \\
Lolium spp. & 2.00 & 38.89 & 2.34 & 0.71 \\
Vaccaria pyramidata & 1.64 & 22.22 & 7.61 & 2.54 \\
\hline
\end{tabular}

Çizelge 2 incelendiğinde Şanlıurfa il genelinde yaygın ve yoğun olan türler sırasıyla $A$. sterilis, $S$. arvensis, C. arvensis, Lolium spp., H.spontaneum, Papaver spp. ve G. tricornutum'dur. Tüm ilçelerde dar yapraklı yabancı otlardan $A$. sterilis ve geniş yapraklı yabancı otlardan $S$. arvensis'in Ceylanpınar ilçesi hariç diğer ilçelerde yaygınlıklarının \%50'den ve yoğunluklarının 1 $\mathrm{bitki} / \mathrm{m}^{2 \prime}$ den fazla olduğu görülmektedir.

Şanlıurfa'da 2015-2016 yıllarında yürütülen bu çalışmanın sürvey sonuçları, önceki yıllarda yapılan çalışmalarda yaygın ve yoğun olduğu bildirilen türleri de içermektedir. Şanlıurfa ilinde buğday alanlarında yabancı ot türlerinin belirlenmesiyle ilgili ilk çalışma Zel (1994) tarafından yapılmış, bu çalışmayı sırasıyla Uludağ ve Demir (1997), Bükün (2004), Arslan ve ark. (2016) takip etmiştir.

Uludağ ve Demir (1997) Şanlıurfa ilinde sarıçiçekli Brassicaceae türlerinin belirlenmesiyle ilgili yaptıkları çalışmada rastlama sıklığı; $S$. arvensis \%86.5, N. apiculata'nın \%74.5, M. perfoliatum \%13, I. tinctoria'nın \%67.5 ve $T$. glastifolia \%17 oranında yaygın olduğu bildirilmiştir. Yapılan bu çalışmada; sarı çiçekli
Brassicaceae türlerinin rastlama sıklı̆̆ı; S. arvensis $\% 84.71, N$. apiculata \%2.45, M. perfoliatum'un $\% 9.01$, I. tinctoria \%13.12 ve T. glastifolia \%0.24 oranında yaygın olduğu, belirlenmiştir. S. arvensis ve $M$. perfoliatum türlerinin yaygınlığı Uludağ ve Demir (1997) ile benzer görülürken N. apiculata, I. tinctoria ve $T$. glastifolia türlerinin yaygınlıkları açısından Uludağ ve Demir (1997) ile farklı olduğu görülmektedir. Ayrıca, H. incana; B. orientalis'in Uludağ ve Demir (1997)'e göre önemli oranda yaygın olduğu görülmektedir. Şanlıurfa'da Bükün (2004), Arslan ve ark. (2016) ve Diyarbakır ilinde Özaslan (2011)'ın yaptıkları çalışmada I. tinctoria ve $N$. apiculata'nın rastlama sıklığının düşük olduğu ve bu türlerin yaygın olmayan türler (\%20'nin altında) arasında olduğu bildirilmiştir. Söz konusu farklılığın Uludağ ve Demir (1997)'in sadece hububat - mercimek münavebesinin yapıldığı alanlarda çalışmalarını yürütmelerinden kaynaklanabileceği düşünülmektedir.

Uludağ (1993) Diyarbakır ilinde hububat mercimek münavebesinin görüldüğü alanlarda yaptığı çalışmaya göre; G. tricornutum, A. sterilis, Lolium spp., Papaver spp., S. arvensis ve $N$. apiculata'nın yaygın ve yoğun görülen türler 
olduğunu bildirmiştir. Bu sonuçlara göre $N$. apiculata dışındaki diğer yabancı ot türlerinin Şanlıurfa illerinde yoğun görülen türlerle paralel olduğu belirlenmiştir.

Özaslan (2011), Diyarbakır buğday ekim alanlarında yaptığı sürvey çalışmasında rastlama sıklığı $\% 50$ 'den fazla olan yabancı ot türlerini sırasıyla; S. arvensis, A. sterilis, C. syriaca, $G$. Tricornutum ve $C$. arvensis olduğunu bildirmiştir. $\mathrm{Bu}$ çalışmanın sonuçları S. arvensis, A. sterilis, $G$. Tricornutum ve $C$. arvensis türlerinin yaygınlığı Özaslan (2011) ile paralel olduğu ancak; C. syriaca'nın yaygınlığı açısından farklı olduğu görülmektedir. Gökalp ve Üremiş (2015)'in Mardin ilinin buğday alanlarında yürüttükleri çalışmaya göre $A$. sterilis, $G$. tricornutum ve $S$. arvensis'in rastlama sıklığı $\% 50$ 'den fazla iken; $C$. syriaca'nın \%50'nin altında yaygın görülen türler arasında olduğunu bildirmişlerdir. Yapılan bu çalışmanın Şanlıurfa ili sürvey bulgularının Gökalp ve Üremiş (2015) ile benzer olduğu görülmektedir.

Bükün (2004), Şanlıurfa'nın buğday alanlarında 2003 yılında yürüttüğü çalışmada 24 familyaya ait 90 yabancı ot türünü belirlemiştir. Bu türlerin yoğunluklarına göre sırasıyla; A. fatua 25.16 bitki $/ \mathrm{m}^{2}$, G. aparine $15.3 \mathrm{bitki} / \mathrm{m}^{2}$, S. arvensis 7.48 bitki $/ \mathrm{m}^{2}, V$. pyramidata $6.84 \quad$ bitki $/ \mathrm{m}^{2}, l$. tinctoria 5.35 bitki $/ \mathrm{m}^{2}$, E. capitata $4.95 \mathrm{bitki} / \mathrm{m}^{2}$ ve $F$. officinalis $4.48 \mathrm{bitki} / \mathrm{m}^{2}$; ayrıca diğer türlere göre daha az yoğunluk gösteren türler; Lolium spp. $2.98 \mathrm{bitki} / \mathrm{m}^{2}, C$. arvensis $0.36 \mathrm{bitki} / \mathrm{m}^{2}$ ve $H$. spontaneum $0.06 \mathrm{bitki} / \mathrm{m}^{2}$ yoğunluğuna sahip olduğunu bildirmiştir. Bu türlerin yoğunluğu Şanlıurfa'da 2015 ve 2016 yılında yürütülen çalışmada sırasıyla A. fatua $10.32 \mathrm{bitki} / \mathrm{m}^{2}$, Lolium spp. $4.96 \mathrm{bitki} / \mathrm{m}^{2}$, F. officinalis $4.08 \mathrm{bitki} / \mathrm{m}^{2}, \mathrm{~S}$. arvensis $3.26 \mathrm{bitki} / \mathrm{m}^{2}, \quad H$. spontaneum 3.21 bitki $/ \mathrm{m}^{2}, \quad$ c. arvensis 2.93 bitki $/ \mathrm{m}^{2}, \quad V$. pyramidata $0.91 \mathrm{bitki} / \mathrm{m}^{2}, \quad$ l. tinctoria 0.63 bitki $/ \mathrm{m}^{2}, \mathrm{G}$. aparine $0.58 \quad$ bitki $/ \mathrm{m}^{2}$ ve $E$. capitata 0.22 bitki $/ \mathrm{m}^{2}$ olarak belirlenmiştir. Her iki çalışma arasında geçen 10 yıldan fazla zamanda; A. fatua, G. aparine, S. arvensis, $V$. pyramidata, I. Tinctoria ve E. capitata türlerinin yoğunluğunda azalma olurken $F$. officinalis'in yoğunluğunda çok az değişim olmakta; $C$. arvensis, Lolium spp. ve $H$. spontaneum türlerinin yoğunluğunda ise önemli oranda artış olduğu görülmektedir. Ayrıca Bükün (2004)'ün çalışmasında rastlanmayan $A$. sterilis (11.51 bitki $\left./ \mathrm{m}^{2}\right)$, G. tricornutum (3.05 bitki $/ \mathrm{m}^{2}$ ) türlerinin buğday alanlarında yoğun olduğu belirlenmiştir.

Üstüner ve Altın (2003), Niğde ili buğday alanlarında yaptıkları çalışmada 1 tohumsuz, 12 monokotiledon ve 80 dikotiledon olmak üzere 26 familyaya ait 93 yabancı ot türü saptamışlardır. Araştırmacılar en önemli yabancı ot türleri olarak Convolvulus arvensis, Boreava orientalis, Centaurea solstitialis subsp. solstitialis, Avena fatua, Sinapis arvensis, Polygonum aviculare, Alopecurus myosuroides, Euphorbia helioscopia, Consolida orientalis, ve Vicia sativa'nın yoğun (110 adet $\mathrm{m}^{2}$ ) olduğunu bildirmektedirler. İki farklı ekolojiye sahip yerde yapılan çalışmada da önemli ortak yabancı ot türü olarak $C$. arvensis ve $S$. arvensis'in olması iki türün de kozmopolit türler olmasından dolayı beklenen bir durumdur. Aynı şekilde Niğde'de A. fatua, Şanlıurfa'da ise $A$. sterilis hâkim türler olup iklim özellikleri göz önüne alındığında yine normal bir durumdur. Diğer yabancı türlerinin çoğunluğu genel olarak sürveyin yapıldığı iklime ait türlerdir.

Çukurova bölgesinde buğday alanlarında 10 yıl arayla yapılan iki farklı çalışmanın sonucuna göre daha önce yaygın ve yoğun görülen bazı türlerin yaygınlıklarında azalmalar olurken yoğunluğunda ise artışlar yaşandığı; düşük yoğunlukta olan bazı türlerin zamanla yüksek oranda yoğunluk kazandığı; dolayısıyla 10 yıl önce problem oluşturmayan türlerin baskın hale geçerek sorun oluşturduğu belirtilmiştir. Söz konusu durum, üreticilerin yabancı otlarla mücadeledeki davranışları ve herbisitlerin hatalı kullanımıyla ilişkilendirilmiştir (Uygur, 1997).

Yürütülen çalışmalar sonucunda buğday alanlarında bulunan yabancı otların türleri ve bu türlerin yaygınlık ve yoğunluklarında zaman içerisinde değişimlerin yaşandığı görülmektedir. $\mathrm{Bu}$ değişimlerin birçok nedeni olmakla birlikte Güneydoğu Anadolu Bölgesinde giderek artan yapay göl ve barajların yapılması özellikle de 
suyun tarım alanlarında etkili kullanımıyla bölgede üretim deseninde değişimler yaşanmaktadır. Son yıllarda suya erişim imkânlarının iyileştirilmesiyle yıl içerisinde birden fazla ürün alma imkânı sağlanmıştır. Buğdayın mısır, pamuk münavebesine girmesi; farklı etki mekanizmalarına sahip herbisitlerin de rotasyona girmesini sağlamış olup toprakta kalıcılığı fazla olan aktif maddelerin kullanılması; sulama suyunun karık, yağmurlama ve damla sulama sistemlerinin entegrasyonuyla toprağın sürüm şekillerinde değişimler yaşanmaktadır. Bu durum bölgede bazı yabancı ot türlerinin yaygınlık ve yoğunluklarında artışların görülmesine, bazı yabancı ot türlerinde azalmaların olmasına neden olduğu düşünülmektedir.

\section{Sonuçlar}

Şanlıurfa ilinde yapılan sürvey çalışmaları sonucunda buğday üretim alanlarında 27 familyaya ait 101 cins ve 121 yabancı ot türü belirlenmiştir. Bunların 21 türü dar yapraklı, 100 türü ise geniş yapraklıdır.

$$
\text { Buğday alanlarında yapılan sürvey }
$$

çalışmalarında bir önceki ürünün pamuk veya mısır olduğu tarlalarda yabancı ot yoğunluğunun daha düşük olduğu görülmüştür. Bu durum pamuk veya mısır alanlarında yapılan farklı toprak işleme yöntemleri ve bu alanlarda kullanılan farklı etkiye sahip herbisitlerin yabancı otların tür ve yoğunluklarını etkilemektedir. Sürvey sonuçları ilçelere göre değerlendirildiğinde Avena sterilis ve Sinapis arvensis tüm ilçelerde ilk sıralarda yer alırken, Convolvulus arvensis bunları izlemektedir. $\mathrm{Bu}$ durum buğday alanlarında münavebenin önemini göstermektedir.

Güneydoğu Anadolu Projesi tamamlandığında Şanlıurfa ilinin sulamaya açılan tarım alanlarında geleneksel tarımın yerini modern tarımın alacağı bu nedenle münavebe sisteminin gelişmesi beklenmektedir (Anonim, 2013). Bölgede suya erişiminin artmasıyla birlikte ekolojik koşulların değişmesine bağlı olarak tarımsal üretimde ekonomik olarak zarara neden olan yabancı otların da artacağı ve mevcut olan türlerin yaygınlık ve yoğunluğa bağlı olarak zarar düzeylerinin değişeceği düşünülmektedir (Arslan, 2018). Bu nedenle tarım alanlarında periyodik sürvey çalışmalarıyla yabancı ot popülasyonu takip edilerek, entegre mücadele yöntemleriyle yabancı otların kontrol altında tutulması gerekmektedir.

\section{Kaynaklar}

Acıbuca, V., (2010). Mardin ilinde makarnalık buğday üretim ekonomisi. Çukurova Üniversitesi, Fen Bilimleri Enstitüsü, Yüksek Lisans Tezi, 60s., Adana.

Akkaya, A., (1994). Buğday yetiştiriciliği. Kahramanmaraş Sütçü İmam Üniversitesi Genel Yayın No:1, Ziraat Fakültesi Yayın No:1, Genel Yayın No:1, Ders Kitapları Yayın No:1.

Anonim, (2012). Şanlıurfa il çevre durum raporu. T.C. Şanlıurfa Valiliği Çevre Ve Şehircilik il Müdürlüğü. Erişim:

http://www.csb.gov.tr/db/ced/editordosya/Sanliurfa _icdr 2012.pdf.

Anonim, (2013). Şanlıurfa Çevre ve Şehircilik iı Müdürlüğü İcraat Raporu. Erişim: http://www.csb.gov.tr/db/ced/editordosya/Sanliurfa _icdr2013.pdf

Anonim, (2016). Türkiye istatistik kurumu, bitkisel üretim istatistikleri. Erişim:__ https://biruni. tuik.gov.tr/bitkiselapp / bitkisel.zul

Anonymous, (2016). Food and agriculture organization of the united nations Erişim: http://faostat3.fao.org/ download/Q/QC/E.

Arısoy, H.. ve Oğuz, C., (2005). Tarımsal Araştırma Enstitüleri Tarafından Yeni Geliştirilen Buğday Çeşitlerinin Tarım İşletmelerinde Kullanım Düzeyi Ve Geleneksel Çeşitler İle Karşılaştırmalı Ekonomik Analizi -Konya i̇li Örneği-. Tarım Ekonomisi Araştırma Enstitüsü, Ankara.

Arslan, Z.F., Bilgili, A. ve Altun, A. A., (2016). Şanlıurfa ili buğday tarlalarında belirlenen önemli yabancı otlar. Uluslararası Katılımlı VI. Bitki Koruma Kongresi (5-8 Eylül 2016, Konya) Bildiriler, 846.

Arslan, Z.F., (2018). Şanlıurfa ili Pamuk Tarlalarında Sulama Sonrası Yabancı Otlar ile ilgili Yaşanan Değişimler, Sorunlar ve Çözüm Önerileri. Harran Tarım ve Gıda Bilimleri Dergisi, 22(1): 109-125

Bilgir, S., (1965). Ege bölgesi hububat tarlalarında görülen önemli yabancı otlar ve savaş imkanları üzerinde bazı incelemeler. Tarım Bakanlığı Yayınları, Teknik Bülten, No: $14,63 \mathrm{~s} .$, İzmir.

Bora, T. ve Karaca, İ., (1970). Kültür bitkilerinde hastalık ve zararlıların ölçülmesi. Ege Üniversitesi, Ziraat Fakültesi Yardımcı Ders Kitabı Yayın No: 167, 43s., İzmir.

Bozkan, N., (2013). Konya ili buğday un fabrikalarından elde edilen yabancı ot tohumlarının tespiti ve hayvansal besin değerleri. Selçuk Üniversitesi, Fen Bilimleri Enstitüsü, Yüksek Lisans Tezi, 78 s., Konya.

Bozkurt, M., (2018). Muş İlinde Buğday Ürününe Karışan Yabancı Ot Tohumlarının Belirlenmesi. İnönü 
Üniversitesi, Fen Bilimleri Enstitüsü, Yüksek Lisans

Bükün, B., (2004). The weed flora of winter wheat in Şanlıurfa, Turkey. Pak. J. B. Sci., 7 (9) 1530- 1534.

Davis, P.H., (1965-1988). Flora of Turkey and the east eagean islands. Edinburg University Press, Volume; 1-10, Edinburg. UK.

Direk, M. ve Gül, A. , (2003). Konya ticaret borsasında buğday fiyat oluşumunu etkileyen faktörler. Ticaret Borsası Dergisi, Sayı: 16, Konya.

Gökalp, Ö. ve Üremiş, ì., (2015). Mardin buğday ekim alanlarında bulunan yabancı ot türlerinin, yaygınlıklarının ve yoğunluklarının belirlenmesi. Mustafa Kemal Üniversitesi Ziraat Fakültesi Dergisi 20 (1) 13-22.

Güncan, A., (2016). Yabancı otlar ve mücadele prensipleri. Güncelleştirilmiş ve ilaveli altıncı baskı), Selçuk Üniversitesi Ziraat Fakültesi, 311s., Konya.

Gürsu, Z.Ş. ve Kara, A., (2016). Kırklareli ili buğday ekim alanlarında görünen önemli yabancı ot türleri, yoğunluklar ve rastlama sıklıklarının belirlenmesi. Uluslararası Katılımlı Türkiye VI. Bitki Koruma Kongresi, 5-8 Eylül 2016, 847s., Konya.

Karaca, M., (2010). Yatık gökbaş (Centaurea depressa Bieb.) ve kokarot (Bifora radians Bieb.)'un bazı biyolojik özellikleri ve Konya yöresinde buğdayda ekonomik zarar eşiklerinin tespiti. Selçuk Üniversitesi, Fen Bilimleri Enstitüsü, Doktora Tezi, 149s., Konya.

Kaya, Y. ve Zengin, H., (2000). Pasinler ovasındaki buğday tarlalarında sorun oluşturan yabancı otlarla, rastlanma sıklıkları, hayat formları ve fitocoğrafik bölgelerinin belirlenmesi. Türkiye Herboloji Derg., 3 (1) $17-26$.

Kuntay, S., (1944). Türkiye hububat mahsulu içinde tohumları bulunan yabancı otlar üzerinde araştırmalar. Ankara Yüksek Ziraat Enstitüsü Dergisi, 2 (1) 220-225, Ankara.

Kün, E., (1996). Tahıllar-I (Serin İklim Tahılları). Üçüncü baskı, Ankara Üniversitesi, Ziraat Fakültesi Yayınları, Yayın No:1451, Ankara, 431s.

Mennan, H., (1993). Samsun ili buğday ekim alanlarında görülen yabancıot türlerinin belirlenmesi ve önemli türlerin çimlenme ve gelişme biyolojilerinin araştırılması. Ç.Ü. Fen Bil. Ens., Yüksek Lisans Tezi, Adana.

Orel, E., (1996). Çukurova Bölgesi buğday ve mısır ekim alanlarında bazı ekolojik faktörlerin göstergesi olabilecek yabancı ot türlerinin saptanması. Ç.Ü., Fen Bil. Enst., Yüksek Lisans Tezi, Adana.

Özaslan, C., (2011). Diyarbakır ili buğday ve pamuk ekim alanlarında sorun olan yabancı otlar ile üzerindeki fungal etmenlerin tespiti ve bio-etkinlik potansiyellerinin araştırılması. Selçuk Üniversitesi, Fen Bil. Enst., Doktora Tezi, Konya.

Özer., Z., Kadıoğlu, İ., Önen, H. ve Tursun, N., (1998). Herboloji (Yabancı ot bilimi), 2. Baskı. Gaziosmanpaşa Üniversitesi, Ziraat Fakültesi Yayınları No: 20, Kitaplar Serisi No: 10, 403s., Tokat.

Pamukoğlu, Z., (2011). Kahramanmaraş kırmızı biber
Tezi, 48 s., Malatya.

alanlarında sorun olan yabancı otlar ve bunlarla mücadelede kritik periyodun belirlenmesi. Kahramanmaraş Sütçü İmam Üniversitesi, Fen Bilimleri Enstitüsü, Yüksek Lisans Tezi, Kahramanmaraş.

Sırma, M. ve Güncan, A., (1997). Tokat ve yöresinde buğday ekim alanlarında sorun oluşturan yabancı otlar ve önemlilerinden bazılarının topluluk oluşturma durumları üzerine bir araştırma. Türkiye II. Herboloji Kongresi (1-4 Eylül 1997, İzmir-Ayvalık) 289-296.

Taştan, B. ve Erciş, A., (1991). Orta Anadolu bölgesi buğday ekim alanlarında gözlenen yabancı otların yayılış ve yoğunlukları üzerinde araştırmalar. Bitki Koruma Bülteni, 31: 39-60.

Tepe, I., (1997). Türkiye'de tarım ve tarım dışı alanlarda sorun olan yabancı otlar ve mücadelesi. Yüzüncü Yıl Üni., Zir.Fak. Yayın No:18, $225 \mathrm{~s}$.

Tursun, N., (2002). Kahramanmaraş ili ve ilçelerinde buğday ekim alanlarında sorun olan yabancı otların belirlenmesi. Türk. Herb. Derg., 5 (1) 1-11.

Uludağ, A., (1993). Diyarbakır ve yöresinde buğday, mercimek kültürlerindeki önemli yabancı otların dağılışı ve bunların biyolojik özellikleri üzerinde araştırmalar. Cumhuriyet Üniversitesi, Fen Bilimleri Enstitüsü, Yüksek Lisans Tezi, Tokat.

Uludağ, A. ve Demir, A., (1997). Güneydoğu Anadolu Bölgesi'nde Hububat Mercimek Münavebe Alanlarında Bulunan Bazı Turpgiller (Brassicaceae)'in Belirlenmesi. Türkiye II. Herboloji Kongresi (1-4 Eylül 1997, İzmir-Ayvalık) 385-389.

Uluğ, E., Kadıoğlu, ì. ve Üremiş, ì., (1993). Türkiye'nin yabancı otları ve bazı özellikleri. T.K.B. Adana Zirai Mücadele Araştırma Enstitüsü, Yay. No: 78, 513s., Adana.

Uygur, F.N., (1985). Untersuchungen zu art und bedeutung der verunkrautung in der Çukurova unterbesonderer berücksichtigung von Cynodon dactylon (L.) Pers. und Sorghum halepense (L.) Pers. PLITS 1985/3 (5), 169 p., Stuttgart.

Uygur, S., (1997). Çukurova Bölgesi yabancı ot türleri, bu türlerin konukçuluk ettiği hastalık etmenleri ve dağılımları ile hastalık etmenlerinin biyolojik mücadelede kullanılma olanaklarının araştırılması. Ç.Ü., Fen Bil. Enst., Doktora Tezi, Adana.

Üstüner, T. ve Güncan, A. (2002). Reserchs on weed species which are problem density and importance with association in potato fileds of Niğde province. Turkish Journal of Weed Science, 5 (2) 30-42.

Üstüner, T. ve Altın, N.B. (2003). Niğde yöresinde buğdayda sorun olan yabancı otlar ve yoğunlukları. Türkiye Herboloji Dergisi, 6(2): 32-44.

Zel, M., (1994). Doğu ve Güneydoğu Anadolu Bölgeleri hububat tarlalarında bulunan yabancıotların dağılımı ve ortalama yoğunlukları. Türkiye Fitopatoloji Derneği Yayınları, Yayın No:8, İzmir.

Zimdahl, R.L., (2018). Fundamentals of Weed Science, 5th Edition, Academic Press, 758p. 